\title{
Internationalization of Information Systems Research and Teaching
}

\author{
Armin Heinzl • Robert Winter • Martin Bichler
}

Published online: 19 May 2015

(C) Springer Fachmedien Wiesbaden 2015

\section{Introduction}

In our editorial of the December issue of BISE in 2014, we discussed standards for assessing the quality of research in our community (Bichler et al. 2014). In the second issue of 2015, we offered our thoughts on the impact of disciplinary research results on practice (Bichler et al. 2015). Whereas we received little feedback from our readers on the first issue, we have received concise positive feedback on our second issue for which we would like to express our gratitude towards the respective colleagues.

In the current issue, we will articulate some thoughts about a phenomenon that we believe is the key to research and teaching in our community: Internationalization. We will contemplate several modes of internationalization and comment on them. These modes depict particular forms or varieties of exporting or importing knowledge about research or teaching contexts.

Internationalization undoubtedly offers a huge potential for our community to extend its impact beyond the own geographical spheres on the one hand, and allows to import

Prof. Dr. A. Heinzl ( $\square)$

Chair of General Management and Information Systems, University of Mannheim, 68161 Mannheim, Germany

e-mail: heinzl@uni-mannheim.de

Prof. Dr. R. Winter

Institute of Information Management, University of St. Gallen, Müller-Friedberg-Strasse 8, 9000 St. Gallen, Switzerland e-mail: robert.winter@unisg.ch

Prof. Dr. M. Bichler

Decision Sciences and Systems, Department of Informatics, Technische Universität München, Boltzmannstr 3, 85748 Munich, Germany

e-mail: bichler@in.tum.de new ideas from other parts of the world that can advance our research and teaching on the other hand. Despite all these benefits, internationalization also bears the risk that our own traditions and standards become marginalized by a broader mainstream.

Along this vein, we want to discuss internationalization in general, and the role that the BISE journal can play in distributing research results in areas where our community is strong. There are topics which might not (yet) be considered popular in other areas of the world but that we find important and relevant. This journal should assist us to shape our own agenda and disseminate our ideas-both within our community and beyond.

\section{Internationalization Modes}

Internationalization in our context can be characterized as an expansion or transfer of research and teaching activities beyond the geographical boundaries of a national community. Since BISE has its roots in the German-speaking countries, ${ }^{1}$ a transfer of research and teaching activities to other language communities and regions can be described as internationalization. The degree or scope of internationalization can be characterized by the geographical distance involved in this expansion. A large degree of internationalization thus means an expansion of research and teaching activities to multiple and distant communities in other regions of the world.

\footnotetext{
1 These countries are often referred to as the DACH countries, an acronym based on the three largest countries where German is spoken: $\mathrm{D}=$ Germany, $\mathrm{A}=$ Austria and $\mathrm{CH}=$ Switzerland. Considering that Liechtenstein, parts of Belgium, and Northern Italy also speak German, we will refer to the language community rather than nations in the following unless otherwise stated.
} 
It is often overlooked that internationalization is a bidirectional process. It certainly implies transferring research and teaching from the own community to other geographical spheres. In addition, it implies adopting and adapting research and teaching activities from other parts of the world to your own realm. For this reason, we will frame the outward transfer direction as the export of knowledge activities. The inward transfer direction will be labelled the import of knowledge activities.

Let us start to reason about the export of knowledge. We see three primary modes of how our community may export knowledge-publishing research in international outlets, conducting international research projects, and transferring the academics themselves. Publishing research in international outlets is very important. This statement makes two implicit assumptions: (i) Scholars are willing and able to publish results outside their home community, and (ii) the quality of a paper has to convince top international scholars. In internationally renowned journals, more authors compete for the same scarce journal space, and reviewers are supposed to have a larger variety of specialized backgrounds. Foremost, competition and diversity are driven by language access. Compared to the 185 million people in the world who speak German, 1.5 billion people are literate in English (Sprachkreis Deutsch 2012). Since English has become the "lingua franca" during the past decades, most international journals have developed from Anglo-American countries, in particular the United States.

As in neighboring disciplines, an increasing amount of junior and senior academics in our community are publishing their research in international conferences and journals. When we look at this export mode, we are impressed by the progress that has been made in our community. In contrast to the situation 20 years ago, the number of publications in international outlets has grown substantially. Let us offer the following examples. At the International Conference on Information Systems (ICIS), for instance, participants from German speaking countries have become the second largest geographic community behind the US. ${ }^{2}$ We also see more and more scholars who publish their research in international top tier journals. Our penetration in international top journals is not as high as at international conferences but steadily growing. Needless to say that the editorial boards of international journals are becoming more and more permeated by scholars from our community. The extrinsic motivation for this development has been facilitated by the fact that international journals and conferences are better advocated in tenure lists, journal, and conference rankings. The intrinsic motivation is

\footnotetext{
2 The respective numbers can be drawn from final registration reports of the ICIS Insider website (AIS 2015).
}

based on two elements: obtaining feedback from scholars in other communities, and making own results accessible for a larger international community.

Another way of exporting knowledge are international research projects. Under the umbrella of the research programmed by the European Union, for instance, significant activities and projects have been initiated and completed during the past decades. We see colleagues from German-speaking countries well represented in these activities. Since associated nations have the chance to participate, these projects may go beyond the geographic boundaries of the EU, including a great deal of corporate participation. Saying that, two concerns remain. First, conducting research projects with colleagues in international countries beyond the EU framework is solely feasible if bi-lateral funding opportunities exist. We are aware of ongoing and successful German-US projects which are funded by the DFG and NSF, but depending on the origin of your research partner, it may be difficult to find appropriate sources for funding. Second, it should not be overlooked that supra-national research projects are not a value per se. They should be considered as an instrument to set up the resources in order to facilitate high quality publications or patents.

The third mode of knowledge exports relates to the most important resource involved: the academics themselves. We are in fact seeing more and more academic descendants from our community who research and teach in other parts of the world like Australia, the US, Scandinavia, and Asia. Many colleagues move to other areas of the world for more than just a sabbatical. Some of us even qualify for tenure in other countries of the world which requires the highest level of personal mobility.

To sum up, the knowledge export has made significant advances but reflects only one side of the medal of academic internationalization. The other side of the medal is the import of scholarly knowledge. Are we also successful importers? Importing standards and practices from other areas of the world doesn't mean that these should be copied no matter what. It rather means to carefully select and adopt practices which help us in advancing our research and teaching.

The first mode of import is the creation of platforms for international publications in our community. First, we recognize advances in organizing major international conferences in our language community. For instance, the European Conference on Information Systems (ECIS) has been organized in Vienna, Regensburg, St. Gallen, and Münster. All events brought a multitude of international junior and senior scholars to our countries. If our scholars are able to participate in cross-continental conferences abroad, however, why don't we go beyond the European scope? Although ICIS 2015 in Fort Worth will be the first 
one which covers nearly all themes of our home community due to pertinent efforts in the program structure, this conference has not yet been hosted in our region.

Second, a few journals in our community have shouldered the effort of going international. One could argue that the internationalization of former domestic journals is part of a knowledge export strategy. However, we have experienced that this effort requires high quality international editors and submissions, in order to improve the journal's recognition. Substantial efforts have been made by our previous editors of BISE journal. This includes the language change, the re-composition of the editorial board, the financing, and the marketing, just to name a few facets. Our journal has taken bold steps to increase its reach beyond the German-speaking countries, but of course it takes years to establish an international brand recognition. Also, internationalization must not sacrifice the goal of serving our community, which is the first and foremost goal of the BISE journal. We are convinced that both is possible, providing an international journal which at the same time is the community journal of the European BISE community.

Finally, we can also ask how effective we are in attracting international scholars to our Ph.D. programs or in hiring international academics for tenure positions. The first AACSB accreditation report of one of Germany's leading universities started with the sentence "This faculty consists of Germans only". Similar observations can be made for the students in many IS Master programs. Reasons for this phenomenon are manifold, including language barriers, high teaching loads, or compensation. In fact, we are not aware of many institutions in our community which have been able to attract international academics on a significant level. If our aim is to hire the best scholars on our continent and beyond, we need to stimulate more change in our mindsets, and we need to change our working language in order to create more visibility and attractiveness. Privately funded institutions may have a head start to better adopt these changes since they are more competitive with respect to international salaries and also work with lower and more flexible teaching loads. But the recognition of public universities which have been introducing international career models (including, but not limited to tenure track models, associate professorships) might compensate for this gap. Being internationally flavored is, however, a different thing than being truly international-and probably not enough to compete against the most established schools in the long run. Students with an international ambition are likely to prefer institutions with a renowned international faculty.

\section{Conclusion}

Of course, the BISE journal cannot support all modes of internationalization stated above. But we would like to support the process of knowledge import and export for research results in our discipline without sacrificing substantial and well-established research traditions and values of our home community. We can and should leverage our local community tradition of problem-solving research, i.e., of proposing and evaluating innovative IS artifactswhich has a lot in common with design science research. The combination and hopefully integration of theorizing existing IS phenomena and designing innovative improvements promises to broaden and enrich the prevailing spectrum of IS research.

We reach out to the international community by sharing and further improving our research tradition that already prevails in many countries (Winter 2008). According to the mission of BISE, we would like to attract research that focuses on theory and technology (Chmielewicz 1994), i.e., on understanding existing worlds and building better ones. Every technology has to adhere to the underlying theoretical properties of its material and behavioral elements. Any IS related theory which cannot be transformed into technology or other tangible actions runs the risk of being invaluable. Thus, our philosophy is rooted in diversity and pluralism-not particularism or mono-method approaches. Information Systems engineering is and will be one key element.

Our community represents a large group of academics with more than 57 years of research traditions. We have strong fields of research with substantial contributions. These fields of research might not have the same popularity in other parts of the world. We believe that we need an internationally accepted journal to set our research agenda. At the same time the journal implements international research standards and is therefore importing practices, which hopefully help our community to reach out to scholars in other parts of the world.

To sum up, we do not aim at cloning the topics and approaches of mainstream IS journals but rather at including themes which have a long tradition in our community and which have been underrepresented elsewhere. At the same time, we provide a platform for novel research streams, to further develop the quality and diversity of our community. The denominations of our departments illustrate this attempt. Overall, we need to further develop the BISE journal into a recognized international journal that adds a problem-solving flavor to the broad spectrum of IS themes offered. 


\section{References}

AIS (2015) ICIS insider. http://aisnet.org/default.asp?page=ICISInsi der. Accessed 22 April 2015

Bichler M, Heinzl A, Winter R (2014) Diversity and quality of BISE research. Bus Inf Syst Eng 56(6):313-316

Bichler M, Heinzl A, Winter R (2015) Practice impact of IS research. Bus Inf Syst Eng 57(2):87-89
Chmielewicz K (1994) Forschungskonzeptionen der Wirtschaftswissenschaft. Stuttgart

Sprachkreis Deutsch (2012) Die meistgesprochenen Sprachen der Welt. http://sprachkreis-deutsch.ch/2012/05/14/die-meistgespro chenen-sprachen-der-welt/. Accessed 15 April 2015

Winter R (2008) Design science research in Europe. Europ J Inf Syst 17(5):470-475 